\title{
Pathways to an oil-constrained future: analogies with climate change mitigation and adaptation
}

\author{
R. J. Brewster \\ Institute of Sustainable Development and Architecture, \\ Bond University, Australia
}

\begin{abstract}
The global production of oil is predicted to have reached a peak in the first decade of this century and will gradually decline, while demand outstrips the discovery and exploitation of new oil sources. This paper investigates issues of adapting urban development to an oil-constrained future, exploring the analogy between oil depletion and climate change. These issues are two of the global wicked problems this century; however, oil depletion is likely to have greater certainty in its predicted impacts. The terminology of climate change mitigation and adaptation is modified to assess its application to oil depletion actions, referring to recent policy research by Hirsch et al on oil supply mitigation as a case study. The categorisation of the proposed administrative measures and physical options is analysed using a non-metric ordinal scale, to indicate how closely they align with the proposed mitigation and adaptation definitions. It is concluded that while there is some blurring between the categories (in a similar way to global warming actions); the modified terminology is a useful way to categorise and analyse oil depletion actions. Current oil strategies are geared to mitigation actions, but adaptive measures will become much more important in the longer term future as oil supply becomes constrained.

Keywords: climate change adaptation, climate change mitigation, global problem, oil depletion, Peak Oil, sustainable urban development.
\end{abstract}

\section{Introduction}

The future changed dramatically in 2008; the price of oil spiked to US \$147 a barrel prior to the world plunging into a multifaceted financial crisis [1]. The 
price of oil collapsed to less than US\$40, and recovered to around US\$100 a barrel by late 2012; but the global financial crisis lingered. A consensus of views was that the era of cheap oil may end in this decade, as demonstrated by the Association for the Study of Peak Oil and Gas [2], International Energy Agency (IEA) [3] and others (e.g. [4, 5]). It was a time of national reflection on Australian future directions for growth and development [6]. International United Nations-led forums continue ineffectual debates about climate change action and the role of renewable energy to replace oil in mitigating global warming impacts $[7,8]$. The worldwide production of conventional oil will decline while demand outstrips the discovery and exploitation of new oil sources.

The imminence of global Peak Oil prompted a $\mathrm{PhD}$ investigation by the author into the relationship between oil dependency and urban residential development in the Australian context. Part of the investigation was presented by the author [9] to the Wessex Institute of Technology 2011 sixth conference on sustainable development and planning. This paper presents a second part of the research on adapting to the oil-constrained future, drawing on the analogy between oil depletion and the terminology of climate change mitigation and adaptation.

\section{Oil depletion and climate change}

One of the well-reported and commonly known consequences of oil combustion in all its forms is resultant carbon dioxide $\left(\mathrm{CO}_{2}\right)$ and other greenhouse gas emissions that contribute to global warming and climate change. This section addresses the relationship between oil consumption and climate change, particularly in the Australian policy context, and draws on recent reports that are relevant to the author's research.

\subsection{Oil consumption and climate change relationship}

The Intergovernmental Panel on Climate Change (IPCC) [10] estimates that oil contributed a 34.6 per cent share of all energy sources in the total global primary energy supply of 492 Exajoules in 2008. The IPCC 2007 report [11] highlights the seriousness of climate change and the imperative to reduce global $\mathrm{CO}_{2}$ production to limit average global temperature rise to $2^{\circ} \mathrm{C}$. However, the IPCC Assessment Report No 5 due in 2013 is expected to revise predictions such that a range of $3-6^{\circ} \mathrm{C}$ by 2100 will be the more likely scenario, with more drastic consequences for the planet. Climate change is widely regarded as a key global problem. Global problems are not just important problems, or problems that affect many people. Rather they are those problems that affect the whole of the planet, and potentially all of the people who live on it, on a scale and in a manner that are both unsustainable and profoundly inequitable [12].

The 2008 Garnaut Climate Change Review [13] makes recommendations for urgent action to reduce carbon emissions. The report is an excellent primer on climate change and includes the issues of energy security within that context. The review recognises transport, land-use and buildings are major contributors of 
greenhouse gas emissions, and that cities are major centres for energy demand, requiring large quantities of energy in both construction and operation. Implementation of climate change mitigation planning principles should embrace broader sustainable development principles and energy transition to a low carbon economy. This should include consideration of energy supply infrastructure, embodied energy and operational energy demand from buildings, and urban infrastructure. Cities should achieve the form, density and spatial pattern of urban development and associated infrastructure that reduce greenhouse emissions. However, the review does not examine in any detail the issues associated with Peak Oil and future oil depletion, particularly in relation to transport and urban development patterns. A 2011 review of the report [14] takes into account findings of recent climate change research and global conferences, and relevant considerations of the global financial crisis. The update accepts the International Energy Agency forecasts of only a slight decrease in global oil supply from $31.5 \%$ to $28.5 \%$ to 2030 . It also concedes that changes in fuel mix rely on gradual replacement of infrastructure and fleet, which is problematic with a long lead time [14: p. 24]. In contrast, an earlier 2006 study by Droege [15: pp. 60-61] makes a stronger link between climate change and the post-Peak Oil scenario, advocating that preparing cities and regions to:

'strengthen regional and urban economic and energy autonomy, are the most sensible strategies to prepare for both Peak Oil and climate change ... Of these two, Peak Oil poses decidedly more imminent risks to cities and human settlement and, some argue, may well serve to help mitigate climate change, albeit in economically disastrous ways.'

The complexities of the economic, social and environmental consequences of oil depletion extend well beyond the context of urban development noted in the Garnaut review into every facet of modern society and technology. Newman and Jennings [16: p. 37] contend that current trends in urban development are not sustainable under these circumstances:

'The two problems are clearly linked - if cities try to move from oil to 'dirty fuels' like oil shale, tar sands, or coal to liquids, this will be much worse in greenhouse terms. Saving oil on the other hand will be a major contributor to reducing greenhouse [effects].'

Oil dependency and efforts to maintain global oil supply are also emerging global problems. Hence the interlinked issues of oil supply depletion and climate change are arguably two of the key global problems of this century [4, 5]. However, oil depletion is likely to have greater certainty in its predicted impacts, and is more of an immediate threat to the economy and people's lives than climate change [17].

The Australian Senate Inquiry into the nation's future oil supply and alternative transport fuels [18] was released during the period of rapidly rising oil prices, but prior to the global financial crisis. The report was prompted by the question of 'Peak Oil' and made a detailed study into the peaking of global oil supply and the demand implications for Australia. The Peak Oil timing uncertainty, demand inelasticity causing high volatility in prices, calls for prudent action to reduce oil dependency and mitigate greenhouse emissions. Alternative 
fuels have energy (and environmental) cost and emissions penalties [18: p. xii]. These views are echoed in a similar study: Queensland's Vulnerability to Rising Oil Prices Taskforce Report [19]; and Oil Vulnerability Strategy/Action Plan for Queensland research paper by Waller [20]. The Waller paper overviews a range of critical issues and poses broad principles for mitigation strategies. One of the key messages is that the Queensland economy is protected by its large coal, coal seam gas and natural gas resource endowments, which 'provide a natural hedge against the oil price outlook' [20: p. 10]. The author's view is that this 'soft' message overlooks the obvious reliance on future clean coal technology to lower $\mathrm{CO}_{2}$ gas emissions. It also seeks to perpetuate the exploitation of fossil fuels.

The Waller paper also goes soft on the household petrol price rise impacts, even though it acknowledges the vulnerability of low density outer suburban living. It suggests adverse equity impacts may need some offsetting policy measures. In contrast, the modelling of the road transport impacts warrants 'a major response in terms of reduced oil-based liquid fuel use, delivered primarily via sharply increased fuel efficiency and fuel switching' [20: p. 6]. Of course fuel switching is not simply choosing a different pump at the service station, without wholesale vehicle modification to gas (LPG/LNG/CNG), or hybrid battery/plug-in electric energy sources, complemented by the new fuel distribution system. The magnitude of the fuel demand in Queensland is such that 'total transport usage is projected to increase by $50 \%$ by 2030 , from some 7,300ML to over 11,000ML' [20: p. 23] set out in Figure 7 in the report and reproduced at Figure 1.

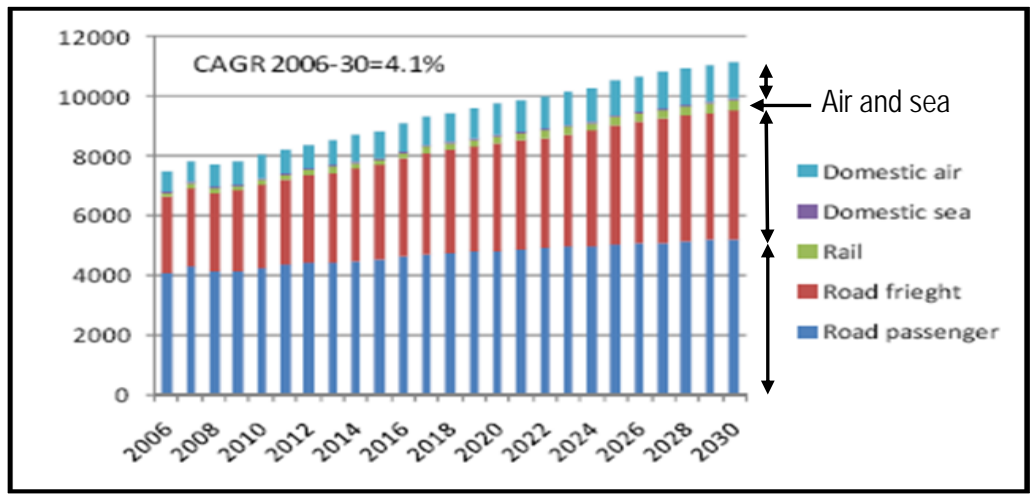

Figure 1: Queensland's transport oil demand, 2006-30 (million litres) [20].

\subsection{Global warming impacts}

In relation to the built environment, the global warming impacts are evenly spread across a large number of building materials. Steel, bricks, concrete and aluminium are the largest contributors because of the embodied energy inputs to the production of these materials. The dominant contributor to global warming is $\mathrm{CO}_{2}$; the only other significant contributor being methane emissions from landfill of organic materials, principally wood. 
The estimate by the Australian Greenhouse Office (AGO) and RMIT[21] of greenhouse emissions from building construction at $14 \%$ is broadly in line with other studies which have found the direct energy used on site to assemble the building is approximately $5-13 \%$ of total embodied energy [22: p. 2]. The AGO estimates that 'oil will make up approximately 32\% of energy use in building materials and construction (two-thirds of this is direct energy use in construction) [21: p. 39]. Natural gas is projected to be $22 \%$ of energy in building materials by 2055. Oil and gas together are projected to account for some 120 PJ (54\%) of total building energy demand'.

The effort to transfer to alternative energy sources for power generation is indicated in a US National Petroleum Council (NPC) [23] presentation on energy futures. It includes a comparison of actions to mitigate the equivalent of one Gigaton per annum of carbon generation, shown at Figure 2 [23: slide 30]. The examples represent a huge effort (currently all depending on the oil economy) needed in developing and in many developing countries, if a global response is to restrict average temperature rise to $2^{\circ}$ in the most optimistic IPCC scenarios.

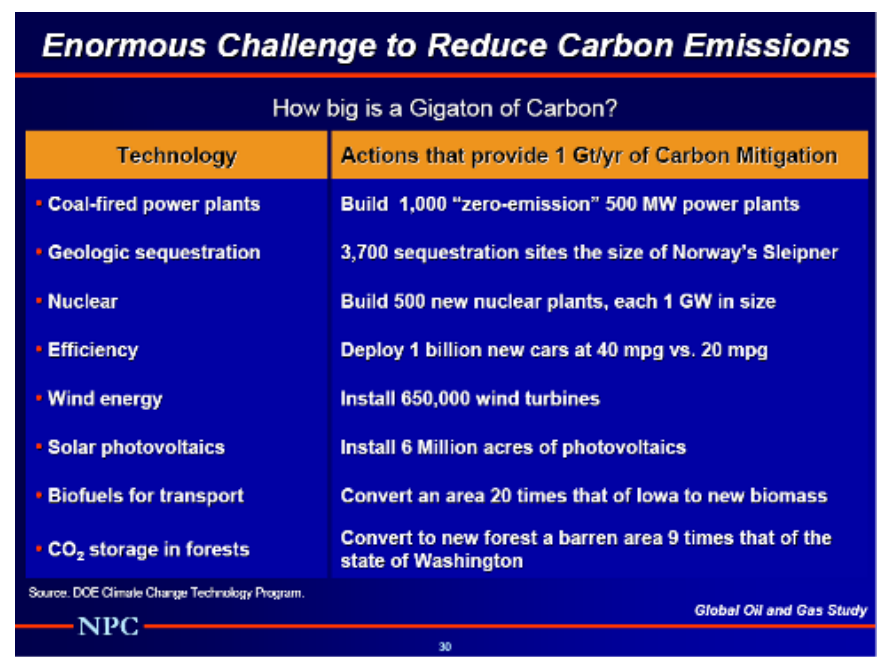

Figure 2: US National Petroleum Council 2008: carbon offset comparisons [23].

\section{Oil and global warming mitigation and adaptation analogy}

\subsection{Mitigation and adaptation terminology}

The terminology used in climate change research and policy makes a distinction between mitigation and adaptation and is fairly well understood (e.g. [3, 11, 13]). This terminology is also loosely used in literature and policies dealing with oil depletion, mainly as mitigation strategies. This can be confusing because actions to mitigate oil depletion are applied both to conserving supply and finding 
alternatives. However, the author considers the terminology is a reasonable analogy to analyse Peak Oil response actions, but needs to be modified for oil.

Terms for climate change are defined by the IPCC [11: p. 871] as:

Mitigation Actions that reduce the impact of human activity on the sources of greenhouse gases or enhance their sinks, aimed at reducing the extent of global warming.

Adaptation The process of adjustment to climate changes that will occur despite efforts to reduce greenhouse gas emissions. Adaptation planning actions can adjust natural or human systems in response to climatic stimuli or their effects, which moderates harm or exploits beneficial opportunities. These actions will contribute to increasing resilience of human settlements to climate change.

Adaptive The ability of social, economic, environmental, institutional

Capacity and the political systems to adjust to change, moderate potential damage, take advantage of opportunities, and cope with the consequences.

Resilience The ability of a social or ecological system to absorb disturbances while retaining the same basic infrastructure and ways of functioning, the capacity for self-organisation and the capacity to adapt to stress and change [24].

There is also a category of dual-purpose actions that have aspects of both mitigation and adaptation; or they are complex and difficult to allocate. Transformation of these terms to apply to future oil supply constraints in the context of urban development could be defined in the following proposed terms:

\section{Oil demand mitigation:}

Conserving oil supply and reducing price vulnerability

\section{Oil supply adaptation:}

Urban development less dependent on oil supply and adaptive living to increase resilience

\section{Adaptive capacity:}

Adjusting systems to be resilient to decreasing oil supply and higher pricing structure
Actions that reduce the impact of land development and building construction activities on global oil demand, aimed at prolonging oilfield production and reducing the extent of vulnerability in oil supply and pricing.

The process of adjustment to globally reducing oil supply that will occur despite efforts to reduce oil demand. Adaptive actions adjust land development and building construction activities in response to oil supply shortages or their secondary effects, which moderates the extent of supply vulnerability and increases resilience. It also includes lifestyle change to adaptive living.

The ability of social, economic, environmental, political, and institutional systems to adjust to change in oil supply and pricing vulnerability, moderate potential damage, take advantage of opportunities, and cope with the consequences of reducing oil supply. These actions will contribute to increasing resilience of human settlements to oil supply vulnerability and depletion. 


\subsection{Mitigation or adaptation actions?}

If an oil-related material can be produced, or an oil-related process can be undertaken, in a more fuel/energy efficient way, the action becomes one of mitigating the vulnerability. If a suitable substitute material or alternative process is available, the action is more one of adapting to the vulnerability. As in climate change actions, however, these notional distinctions become blurred in relation to oil vulnerability; because actions to mitigate (e.g. use less oil) can also be applied to adaptation (e.g. adopt the use of alternatives). This is compared to climate change, where an increase in greenhouse gas emissions can result from several unrelated causes and lead to a range of multivariate consequences. These effects range from global warming and more extreme weather events to sea level rise and ocean acidity [11]. Some effects may be both beneficial and adverse, such as the geographic shift in temperate climatic zones. However, there is not a similar body of research and policy in relation to oil policy that deals separately with mitigation and adaptation strategies in a consistent analytical manner.

A search of the literature in 2010 failed to reveal any research comparing oil and climate change mitigation and adaptation. Fortunately a book released at the 2010 World Oil Conference in Washington DC provides a case study. It follows a 2007 report on Peak Oil implications and the same authors Hirsch et al. [25] address oil mitigation issues in two ways-administrative measures and physical options. The primary objective is to address the need that 'an uninterrupted supply of moderately priced oil is essential to world economic wellbeing, let alone growth' [25: p. 84]. The thrust of this strategy appears to attempt to mitigate depletion to maintain a business as usual approach to the use of oil in the American context. The investigation into the 'impending world energy mess' is summarised in three aspects [25: p. 231]:

a. The impending decline of world oil production, which the world has yet to fully comprehend, let alone prepare for;

b. The intoxication with renewable energy, which is incapable of providing the world with large amounts of liquid fuels or electric power at costs comparable to petroleum alternatives;

c. Climate change, the consideration of which has overshadowed a multitude of energy decisions, in spite of the fact that there are large questions in the science.

The authors conclude that even if all the suggested oil mitigation measures were implemented quickly, 'oil shortages will almost certainly grow more rapidly than our best mitigation efforts, and this implies significant world shortages before our mitigation efforts catch up and surpass world oil production declines' [25: p. 233]. This conclusion implies that liquid fuel supply will somehow match future demand-albeit on a reduced scale-from biomass, oil shales, tar sands, gas-to-liquid and algae sources [25: pp. 145-172]. The authors envisage transport fuels would be complemented by the conversion to natural gas and electrification of vehicles; and clean coal, gas and nuclear power generation, supplemented by solar and wind power. They take a pessimistic view about 'the concept of renewable energy with its promise of eternal energy for nature' [25: p. 234]. as being incapable of satisfying the overall energy needs of USA. 
Hence no specific distinction is made between oil mitigation and adaptation measures. In a personal communication at the 2010 World Oil Conference, the lead author Robert Hirsch [26] reinforced this view by not holding an opinion about any relevance of a separation of these aspects and tended to combine the two terms. The author considers that a closer examination is warranted to determine if some of the suggested 'mitigation' options are more aligned to 'adaptation' as described in the above proposed definitions, despite the lack of semantic separation. Table 1 below uses the Hirsch program administrative measures and physical options-with a non-metric ordinal scale-to indicate how closely they align with the mitigation and adaptation definitions proposed above. Categorisation is based on the author's climate change and Peak Oil research. The table demonstrates that most (9 out of 16) Hirsch proposed mitigation measures could also have varying relevance to adaptation measures.

Administrative measures: these cover 'options that can be implemented by individuals, organizations and governments, either voluntarily of via mandates'. They include rationing of oil supplies, car-pooling and tele-commuting [25: p. 85].

Physical mitigation measures: these include deployment of more fuel efficient vehicles; more reliance on heavy oil and oil sands, gas to liquids, coal to liquids, and enhanced oil recovery technology [25: p. 111]. A range of options are discussed for alternative fuels, electric vehicles and stationary power generation.

The author considers Options such as telecommuting, plug-in electric vehicles, hydrogen fuel cells, solar and wind power to be adaptive strategies to live with less oil supply. Other options such as plug-in hybrid electric vehicles and natural gas (both for transport and stationary power) are slightly more aligned to mitigation. This is because they are both exploiting a finite fossil fuel to maintain a business as usual approach to transport and motorised machinery. Rationing of oil supplies is important to both aspects. The other relevant measures are more aligned to mitigating oil demand to conserve future supply.

Hirsch et al note that 'performing a meaningful analysis of the best-case mitigation of world oil production decline is the selection of the most important variables, while making reasonable assumptions on other important factors'. They acknowledge that analysis is hampered by the 'multitude of complexities and unknowns' surrounding oil production decline, but postulate a 'worldwide crash program' of mitigation that would start instantaneously from a business as usual situation [25: p. 109]. The Hirsch program assumes all countries would act with equitable goodwill, which the authors caution is unlikely as oil exporting nations will withhold supplies to suit national objectives, including their own longer term resource needs. This underlying caution supports the author's view that the act of mitigating oil demand at the local level may actually cause an economic disadvantage, while allowing a business as usual approach elsewhere, at both intra- and inter-national scales. Hence an adaptation program is likely to have fewer adverse impacts. 
Table 1: Comparison of Hirsch proposed measures with the author's proposed mitigation-adaptation definitions on a non-metric ordinal scale.

\begin{tabular}{|c|c|c|}
\hline \multirow[t]{2}{*}{$\begin{array}{c}\text { Mitigation options: } \\
\text { proposed by Hirsch et al [25] }\end{array}$} & \multicolumn{2}{|c|}{$\begin{array}{c}\text { Descriptive definitions: } \\
\text { proposed by Roger Brewster }\end{array}$} \\
\hline & Mitigation action & Adaptation action \\
\hline \multicolumn{3}{|c|}{ Administrative measures: } \\
\hline $\begin{array}{l}\text { Pricing and allocation } \\
\text { controls for rationing of oil } \\
\text { supplies }\end{array}$ & $\mathrm{XX}$ & $\mathrm{XX}$ \\
\hline Car-pooling & $X X$ & $\mathrm{X}$ \\
\hline Telecommuting & $\mathrm{XX}$ & $\mathrm{XXX}$ \\
\hline \multicolumn{3}{|c|}{ Physical measures: } \\
\hline $\begin{array}{l}\text { More fuel efficient vehicles } \\
\text { including: } \\
\text { - hybrid electric vehicles } \\
\text { - plug-in hybrid electric } \\
\text { vehicles } \\
\text { - plug-in electric vehicles }\end{array}$ & $\begin{array}{l}\text { XXX } \\
\text { XXX } \\
\text { XXX }\end{array}$ & $\begin{array}{c}\mathrm{X} \\
\mathrm{XX} \\
\mathrm{XXX}\end{array}$ \\
\hline $\begin{array}{l}\text { More reliance on heavy oil } \\
\text { and oil sands }\end{array}$ & $\mathrm{XX}^{\mathrm{o}}$ & - \\
\hline Enhanced oil recovery & $\mathrm{XXX}$ & - \\
\hline Coal to liquids & $\mathrm{XXX}$ & - \\
\hline $\begin{array}{l}\text { Alternative transport fuel } \\
\text { options: } \\
\text { - Natural gas } \\
\text { - Gas from shale and coal } \\
\text { seams } \\
\text { - Biofuels } \\
\text { - Hydrogen fuel cells }\end{array}$ & $\begin{array}{c}\text { XXX } \\
X^{\circ} X^{\circ} \\
X X X^{\circ} \\
X X\end{array}$ & $\begin{array}{c}X X \\
X^{0} \\
X^{0} \\
X X X\end{array}$ \\
\hline Solar power generation & $\mathrm{XXX}$ & $\mathrm{XXX}$ \\
\hline Wind power generation & $\mathrm{XXX}$ & $\mathrm{XXX}$ \\
\hline $\begin{array}{l}\text { Nuclear power generation - } \\
\text { (Using Thorium cycle only) }\end{array}$ & $\begin{array}{c}\mathrm{XXX} \\
\text { (subject to waste } \\
\text { disposal issues) }\end{array}$ & $\begin{array}{c}\text { XXX } \\
\text { (subject to waste } \\
\text { disposal issues) }\end{array}$ \\
\hline
\end{tabular}

Key: - not relevant to adaptive actions for transport. X Relevant. XX Highly relevant. $\mathbf{X X X}$ Close fit to proposed definitions. ${ }^{\mathbf{0}}$ Not preferred due to environmental impacts. 


\subsection{Discussion}

The analogy between oil depletion and climate change actions suggests that the proposed set of definitions could (simplistically) be applied to categorise oil depletion measures. As noted above, while the categorisation has a subjective aspect that is open to debate, it is based on the author's climate change professional policy experience and on Peak Oil research. The table indicates that the ' $\mathrm{XXX}$ ' rated measures are considered by the author to most closely fit the proposed definitions in relation to the nominated policy actions or strategies. Interestingly, however, the mitigation ' $\mathrm{XXX}$ ' actions are a much closer fit for 11 of the 16 in the list. Adaptation actions are almost evenly spread: ' $\mathrm{XX}$ ' plus ' $\mathrm{XXX}$ ' actions making up only half the total. There is also a close commonality in relevance between nine of the 16 mitigation and adaptation actions. The above analysis shows that mitigation actions dominate. It also appears to support a view that a notional separation is blurred by cross-cutting measures, as actions to mitigate (conserve oil supply) can also apply to adaptation (using alternatives).

It should be noted that the Hirsch study focuses on transport, and although it is pervasive throughout the economy, the study does not consider the broader aspects of planning and developing the built environment. If these and other social elements were added to the list, the range of adaptive actions would increase to include: inner city living in compact urban form; transit oriented development; behavioural change to a public and active transport focus; alternative and lower embodied energy building materials and construction processes. Renewable energy sources would feature more prominently, with local distribution grids. In the longer term future adaptive measures-including those in table 1-will become much more important as the inevitability of oil supply constraint becomes real. This is also analogous to climate change actions, which have transitioned from mitigation to adaptation as the reality of overshooting the $2^{\circ} \mathrm{C}$ temperature rise appears to be inevitable. It is considered that the modified mitigation and adaptation terminology is a useful way to categorise and analyse oil depletion actions, but in a flexible application of the model.

An adaptive strategy is likely to pose fewer adverse external threats to the national economy. Such a view is in keeping with the notion of oil depletion being a global wicked problem [12]. Future petroleum depletion (including oil and gas) is considered to have most of the characteristics to identify it a global wicked problem. This makes the resolution of the issues at all scales of urban development and levels of government (and internationally) an intractable proposition. Hence there will be economic winners and losers in the post-Peak Oil scenario, which will gradually impact on the economic performance of cities, and could jeopardise the sustainability of future urban development. This rather gloomy scenario is supported by most of the cited commentators and makes an urgent transition to adaptive measures all the more important $[1,4,5,15,16]$. Such adaptive measures must adjust in ways that contribute to increasing resilience of human settlements to oil supply vulnerability and depletion:

- changes in oil supply and pricing vulnerability;

- moderating potential damage; 
- taking advantage of opportunities;

- coping with consequences of reducing supply in an oil-constrained future.

\section{Conclusion}

The analogy between oil depletion and climate change actions is tested by applying a modified set of mitigation and adaptation definitions to a case study to categorise oil depletion strategies. The author considers that the modified terminology is a useful way to categorise and analyse oil depletion actions, but in a flexible application of the model. The analysis of the case study shows that mitigation actions dominate the strategies. It also appears to support a view that a notional separation is blurred by cross-cutting measures, as actions to mitigate depletion (conserve oil supply) can also apply to adaptation (using alternatives).

Using the analogy of mitigation and adaptation aligns Peak Oil research with the widely accepted terminology in climate change research and policy making. It is concluded that the proposed modified mitigation and adaptation terminology is a useful way to categorise and think about oil depletion actions. The definitions warrant further peer review to gain acceptance. While the case study strategies are geared to mitigation actions, adaptive measures will become more important in the longer term future as oil supply becomes constrained.

\section{References}

[1] Rubin, J., Why Your World is About to Get a Whole Lot Smaller: oil and the end of globalization, Random House, New York, 2009.

[2] Association for the Study of Peak Oil and Gas (ASPO), Newsletter No 97 January 2009. Online. http://aspoireland.org/newsletter/

[3] International Energy Agency (IEA), World Energy Outlook 2010, International Energy Agency and Organisation for Economic Cooperation and Development, Paris, 2010.

[4] Heinberg, R., Peak Everything: waking up to the century of decline in Earth's resources, Clairview Books, London, 2007.

[5] Newman, P. Beatley, T. and Boyer, H., Resilient Cities: responding to peak oil and climate change, Island Press, Washington, D.C., pp. 6-21, 2009.

[6] Australian Government, Our cities: the challenge of change, Major Cities Unit, Department of Infrastructure and Transport, Canberra, 2010.

[7] United Nations, Department of Economic and Social Affairs (UN/DESA), World Economic and Social Survey 2009: Promoting Development, Saving the Planet, United Nations, New York. Online. www.un.org/en /development /desa/news/policy/wess-2009.shtml, 2009.

[8] United Nations Framework Convention on Climate Change (UNFCCC), Conference of the Parties (COP 18) 26 November -7 December, 2012.

[9] Brewster, R.J., Significance of global oil depletion to urban residential development, in Sustainability Today,WIT Transactions on Ecology and The Environment, Vol 167ed. C.A. Brebbia, WIT Press, Southampton, ISSN 1743-3541, pp. 151-163, 2011. 
[10] Intergovernmental Panel on Climate Change (IPCC), Special Report on Renewable Energy Sources and Climate Change Mitigation: Summary for Policymakers, Technical Support Unit Working Group III, Potsdam Institute for Climate Impact Research (PIK). Online. www.ipcc.ch/publications_and_data/publications_and_data_reports.shtml\# SRREN. p. 10, 2011.

[11] Intergovernmental Panel on Climate Change (IPCC), Climate Change 2007: Synthesis report. Contribution of Working Groups I, II and III to the Fourth Assessment Report of the Intergovernmental Panel on Climate Change, Core Writing Team, R.K. Pachauri and A. Reisinger (eds), IPCC, Geneva. 2007.

[12] Tanter, R., What are global problems?, Nautilus Institute for Security and Sustainability, RMIT, Melbourne. Online. www.nautilus.org/gps/intro/, 2008.

[13] Garnaut, R., Garnaut Climate Change Review Final Report, Cambridge University Press, Melbourne. Online. www.garnautreview.org.au, 2008.

[14] Garnaut, R., The Garnaut review2011: Australia in the response to climate change, Cambridge University Press, Melbourne, p. 24, 2011.

[15] Droege, P., The Renewable City: a comprehensive guide to an urban revolution, Wiley-Academy, Chichester, pp. 60-61, 2006.

[16] Newman, P. and Jennings, I., Cities as Sustainable Ecosystems: principles and practices, Island Press, Washington, DC; London, p.37, 2008.

[17] UK Industry Taskforce of Peak Oil and Energy Security, The Oil Crunch: Securing the UK's energy future. Online. www.arup.com/_assets/ download/4D6FF5E5-19BB-316E-408B503DFB26ADDB.pdf, 2008.

[18] Australian Senate, Inquiry into Australia's future oil supply and alternative transport fuels: Final Report, Australian Senate Standing Committee on Rural and Regional Affairs and Transport, Canberra, pp. xii-xiii, 2007.

[19] Queensland Parliament, Queensland's Vulnerability to Rising Oil Prices Taskforce Report, Queensland Government, Brisbane, 2007.

[20] Waller, M., Oil Vulnerability Strategy/Action Plan for Queensland: research paper, Heuris Partners Ltd, Brisbane, pp. 6-24, 2008.

[21] RMIT University \& Australia. Dept. of the Environment and Heritage and the Arts, Scoping Study to Investigate Measures for Improving the Environmental Sustainability of Building Materials, Australian Greenhouse Office, Canberra. Online. http://nla.gov.au/nla.arc-85449, p.39, 2006.

[22] Crowther, P., Design for Disassembly to Recover Embodied Energy. In Szokolay, Steven S. (Ed.) The 16th International Conference on Passive and Low Energy Architecture, 22-24 September 1999, Melbourne. Online. http://eprints.qut.edu.au/2846/,1999.

[23] National Petroleum Council (NPC) 2008 Hard Truths-Facing the Hard Truths about Energy: update presentation, Washington. Online. www.npchardtruthsreport.org/presentations08.php, Slide 30, 2008.

[24] Australia, Climate Change Risks to Australia’s Coast: A First Pass National Assessment, Australian Dept. of Climate Change, Canberra, 2009. 
[25] Hirsch, R. L., Bezdek, R. H. and Wendling, R.M., The Impending World Energy Mess: what it is and what it means to you, Apogee Prime, Canada, 2010.

[26] Hirsch, R.L. Personal communication, 8 October 2010, Senior Energy Advisor, Management Information Services, Inc., Washington D.C. 